\title{
Impact of Single-port Laparoscopic Approach on Postoperative Pain and Cosmesis for Acute Appendicitis: A Comparison with Multi-port Laparoscopic Approach
}

Kyeong Eui Kim

Keimyung University Dongsan Hospital

In Soo Cho

Keimyung University Dongsan Hospital

Sung Uk Bae ( $\nabla$ sabiston0000@hanmail.net )

Keimyung University Dongsan Hospital

Woon Kyung Jeong

Keimyung University Dongsan Hospital

Hyung Jin Kim

The Catholic University of Korea

Seong Kyu Baek

Keimyung University Dongsan Hospital

\section{Research Article}

Keywords: Appendicitis, Laparoscopy, Pain, Natural orifice endoscopic surgery, Treatment outcome, Cosmetic techniques

Posted Date: November 16th, 2021

DOI: https://doi.org/10.21203/rs.3.rs-998543/v2

License: (c) (1) This work is licensed under a Creative Commons Attribution 4.0 International License. Read Full License 


\section{Abstract}

Background: Acute appendicitis is the most common surgical abdominal emergency. Single-port laparoscopic appendectomy (SPLA) has been suggested potential advantages including less postoperative pain and better cosmesis. The aim of this study was to compare the postoperative pain and cosmetic outcomes between SPLA and multi-port laparoscopic appendectomy (MPLA) for acute appendicitis.

Materials and methods: The study included 47 patients who underwent SPLA and 51 patients who underwent MPLA for acute appendicitis between August 2014 and November 2017. The patient scar assessment questionnaire (PSAQ) was used to assess cosmetic outcomes.

Results: MPLA involved a longer median operative time than MPLA (60 vs. 47.5 minutes, $p=0.02$ ). There were no apparent differences in the time before diet tolerance, length of hospital stay, inflammatory laboratory findings including C-reactive protein and white blood cell count, and postoperative complication rate. SPLA patients had a smaller total incision length $(2.0 \mathrm{vs.} 2.5 \mathrm{~cm}, \mathrm{p}<0.001)$ and the total number of analgesics used on postoperative day 0 in the SPLA group was significantly lower than that of the MPLA group (1 vs. 1, p=0.011). The PSAQ scores showed that the SPLA group had a better overall outcome than the MPLA group with respect to total score (48 vs. $55 ; p=0.026)$, appearance (15 vs. $18 ; p=0.002$ ) and consciousness ( 8 vs. $10 ; p=0.005)$, but not in the satisfaction with appearance and symptoms subscales.

Conclusion: SPLA is safe and feasible and provides better cosmetic outcomes and less analgesic requirements on the day of surgery compared to MPLA.

\section{Introduction}

Laparoscopic surgery is replacing laparotomy for treating various types of abdominal surgery and has some advantages including reduced blood loss, fewer analgesic requirements, less complications, faster postoperative resumption, and shorter length of hospital stay compared with open surgery. Since laparoscopic appendectomy was first introduced by Semm in 1983 [1], the application of this surgery has expanded to more complex cases including perforated appendicitis and peri-appendiceal abscess. [2-5]

As minimally invasive surgery has rapidly developed in recent years, novel efforts have been aimed at minimizing surgical trauma and improving cosmetic outcomes. These concepts have led to the development of single-port laparoscopic surgery for various kinds of diseases[6-10]. Single-port laparoscopic appendectomy (SPLA) was firstly introduced by Esposito in 1998 and has been suggested potential advantages including better cosmetic outcome, less postoperative pain, and avoidance of possible hemorrhagic complications from injuring epigastric vessels[11-14].

Cosmetic outcomes and evaluation of postoperative pain have been considered as important issues in postoperative quality of life. SPLA requires a larger trans-umbilical incision and some researchers have 
questioned if SPLA might actually cause less pain and better cosmesis compared with multi-port laparoscopic appendectomy (MPLA). To date, evidence to solve this question is still lacking. The aim of our study was to compare the clinical outcomes including cosmesis and postoperative pain between SPLA and MPLA for acute appendicitis.

\section{Materials And Methods}

\subsection{Patients}

Between August 2014 and December 2017, the study enrolled 98 patients who underwent a laparoscopic appendectomy for acute appendicitis (51 in the MPLA group; 47 in the SPLA group). Patients suspected of generalized peritonitis, who was pregnant, who were diagnosed with a disease other than appendicitis after surgery, and who had history of previous major laparotomy such as gastrectomy and hepatectomy, and co-morbidities including cardiopulmonary failure, liver failure or chronic kidney disease were excluded in this study. This study protocol was approved by the Institutional Review Board of the medical center (IRB No. 2021-03-019), and informed consent was obtained from all patients.

\subsection{Evaluation parameters}

Information on patient demographics included age, sex, preoperative white blood cell (WBC) and Creactive protein (CRP), body mass index, type and location of appendicitis, presence of periappendiceal abscess and onset of abdominal pain. The operative outcomes of surgery included operative time, intraoperative bleeding amount, total incision length, diameter and length of appendix, adhesion, intraabdominal fluid collection, intra-abdominal drainage and additional port use. In this study, we defined the port insertion time as the time from skin incision to port placement, laparoscopic procedure time as the time from completion of port placement to port removal after appendectomy, and skin closure time as the time for closing the incisions of port sites. Postoperative outcomes included time to gas out and soft diet, length of stay, pain score using visual analog scale (VAS) 6, 12, and 24 hours after operation, total number of analgesics used on postoperative day 0 and 1 , and inflammatory serum markers including WBC and CRP 12 and 24 hours after operation.

\subsection{Surgical technique}

MPLA required the introduction of a rigid scope through an incision in the umbilicus and two additional incisions were made in the suprapubic area and left lower quadrant abdomen (Figure 1). Patient was placed in supine position with head-down and tilted left-side down. The appendix was exposed and the mesoappendix was divided by sequential use of advanced energy device or monopolar energy device with clipping. The base of appendix was ligated using Endoloop ${ }^{\circledR}$ (Ethicon Endosurgery,Cincinnati, Ohio, USA). Irrigation was performed in the pelvic area, sub-hepatic area, para-colic gutter, and periappendiceal area. Specimens were extracted with sterile bag through umbilical incisional site. Following remove of trocar, the fascia was closed with interrupted sutures using 2-0 vicryl (B. Braun Aesculap AG \& Co KG, 
Tuttlingen, Germany). Skin was closed with interrupted suture using 3-0 nylon or skin stapler, or 4-0 absorbable monofilament suture with sterile strip.

In SPLA, a single 2.0-cm vertical incision was made through the umbilical skin after the base of the umbilical stalk was everted using Allis tissue forcep (Figure 1). The subcutaneous tissue was dissected toward the linea alba and the peritoneum was opened. A single-port was placed in the abdominal cavity through the trans-umbilical incision. The procedure for appendectomy in SPLS was mostly similar to that in MPLS. The resected appendix was extracted through the sterile bag component of the single-port without the use of additional endo-bag. The skin was closed using 3-0 nylon or skin stapler, or 4-0 absorbable monofilament suture with sterile strip.

\subsection{Patient scar assessment questionnaire scores at 12 weeks postoperatively}

The patients filled out the patient scar assessment questionnaire (PSAQ) at 12 weeks postoperatively over the phone (Figure 2). The PSAQ consists of four sub-items following: appearance, consciousness, satisfaction with appearance, and satisfaction with symptoms [13]. Appearance sub-item were evaluated by questions about scar color, width, flatness, texture, shine, and overall appearance. Consciousness subitem was further delineated into itchiness, pain, discomfort, numbness, odd sensations, and overall troublesomeness of symptoms. Satisfaction with appearance sub-item was ascertained by how noticeable the scar was to the patient and to others and by the overall self-consciousness the patient associated with the scar. Satisfaction with symptoms sub-item was assessed according to the satisfaction with numbness of the scar, color, similarity to surrounding skin, and overall appearance. Each sub-item comprises a set of items with four-point categorical responses, with scores ranging from 1 to 4 points ( 1 point is assigned to the most favorable response and 4 points are assigned to the least favorable response).

\subsection{Statistical analysis}

The results were presented as averages with standard deviations, and as frequencies with percentages for categorical outcomes. Categorical variables were analyzed using the Chi-square. Continuous variables were analyzed with independent t-test. P-value of less than 0.05 were considered to indicate statistical significance. The statistical analyses were performed with SPSS statistical software (version 25; IBM Corp., Armonk, NY, USA).

\section{Results}

\subsection{Baseline characteristics}

Baseline characteristics of MPLA and SPLA groups are described in Table 1. There were no statistically significant differences in sex, body mass index, and age distribution between the two groups. Suppurative appendicitis was the most common type in both groups and the proportions of suppurative, gangrenous, 
and perforated appendicitis did not differ statistically between the two groups. Retrocecal position of appendix tip was the most common position in both groups without statistical difference. Two patients (3.9\%) in MPLA group and one patient (2.1\%) in SPLA group had peri-appendiceal abscess. Both groups had no significant difference in onset of symptom ( 1 day vs 2 days, $p=0.780)$, preoperative WBC (12480 vs $12560, p=0.663)$, and $\operatorname{CRP}(1.74$ vs $1.46, p=0.661)$.

\section{TABLE 1}

\section{Baseline characteristics}




$\operatorname{MPLA}(n=51) \quad$ SPLA $(n=47) \quad$ p value

\begin{tabular}{|c|c|c|c|}
\hline Age (years), median (range) & $40(19-66)$ & $39(19-72)$ & 0.490 \\
\hline Sex & & & 0.440 \\
\hline Male & $31(56.4)$ & $24(43.6)$ & \\
\hline Female & $20(46.5)$ & $23(53.5)$ & \\
\hline $\mathrm{BMI}\left(\mathrm{kg} / \mathrm{m}^{2}\right)$, median (range) & $23.5(18.9-40.6)$ & $22.9(16.1-31.7)$ & 0.253 \\
\hline ASA groups, $n(\%)$ & & & 0.427 \\
\hline 1 & $46(90.2)$ & $41(87.2)$ & \\
\hline II & $3(5.9)$ & $5(10.6)$ & \\
\hline III & $2(3.9)$ & $1(2.1)$ & \\
\hline Type of appendicitis, $n$ (\%) & & & 0.213 \\
\hline Supprative & $37(72.5)$ & $29(61.7)$ & \\
\hline Gangrenous & $6(11.8)$ & $12(25.5)$ & \\
\hline Perforated & $8(15.7)$ & $6(12.8)$ & \\
\hline Location of appendicitis, n (\%) & & & 0.443 \\
\hline Retrocecal & $37(72.5)$ & $34(72.3)$ & \\
\hline Pelvic & $4(7.8)$ & $2(4.3)$ & \\
\hline Retroperitoneal & $1(2.0)$ & $4(8.5)$ & \\
\hline Antececal & $9(17.6)$ & $7(14.9)$ & \\
\hline Peri-appendiceal abscess & $2(3.9)$ & $1(2.1)$ & 0.607 \\
\hline Onset of symptom & $1(1-7)$ & $2(1-10)$ & 0.780 \\
\hline WBC at admission & 12480(3710-20010) & $12560(4580-34200)$ & 0.663 \\
\hline CRP at admission & $1.74(0.01-15.71)$ & $1.46(0.01-26.94)$ & 0.661 \\
\hline
\end{tabular}

MPLA, Multi-Port Laparoscopic Surgery; SPLA, Single-Port Laparoscopic Surgery; ASA, American Society of Anesthesiologists; BMI, body mass index; WBC, white blood cell; CRP, C-reactive protein

\subsection{Perioperative outcomes}

The median total operative times was significantly longer in MPLA group than SPLA group (60 min vs $47.5 \mathrm{~min}, \mathrm{p}=0.02$ ) (Table 2). In detail, medians of port insertion time and laparoscopic procedure time in SPLA group were shorter than that in MPLS group ( 5 and 27.5 min vs. 6 and 41 min, $p=0.05$ and $p<0.01$, 
respectively), whereas the median of skin closure time was significantly longer in SPLA group than MPLA group (13 min vs $10 \mathrm{~min}, \mathrm{p}<0.01$ ). Diameter and length of appendix were not significantly different between two groups. The total incision length was shorter in SPLA group compared to MPLA group $(20.1 \mathrm{~mm}$ vs $27.3 \mathrm{~mm}, \mathrm{p}<0.001)$. Intra-abdominal drainage was required in 9 patients in each group. Seven patients (14.9\%) who were treated with SPLA needed an additional $2 \mathrm{~mm}$ port insertion and one patient (1.9\%) who were treated with MPLA needed additional $5 \mathrm{~mm}$ port placement for the efficient traction due to severe inflammation and adhesion.

\begin{tabular}{|c|c|c|c|}
\hline \multicolumn{4}{|c|}{$\begin{array}{c}\text { TABLE } 2 \\
\text { Perioperative outcomes }\end{array}$} \\
\hline & MPLA $(n=51)$ & SPLA $(n=47)$ & $\mathrm{p}$ value \\
\hline Total operation time (min), median (range) & $60(30-135)$ & $47.5(28-100)$ & 0.02 \\
\hline Port insertion time (min), median (range) & $6(3-40)$ & $5(2-13)$ & 0.05 \\
\hline Laparoscopic procedure time (min), median (range) & $41(15-110)$ & $27.5(14-85)$ & $<0.01$ \\
\hline Skin closure time (min), median (range) & $10(3-25)$ & $13(5-20)$ & $<0.01$ \\
\hline Total length of incision (cm), median (range) & $2.5(1.0-5.0)$ & $2.0(1.2-4.0)$ & $<0.01$ \\
\hline Diameter of appendix (mm), median (range) & $10(5-30)$ & $10(8-20)$ & 0.586 \\
\hline Length of appendix (cm), median (range) & $7(4-12)$ & $7(3-11)$ & 0.958 \\
\hline Intra-abdominal drainage & $9(17.6 \%)$ & $9(19.1 \%)$ & 0.848 \\
\hline Additional port insertion & & & 0.011 \\
\hline $5 \mathrm{~mm}$ & $1(1.9)$ & 0 & \\
\hline $2 \mathrm{~mm}$ & 0 & $7(14.9)$ & \\
\hline
\end{tabular}

\subsection{Postoperative operative outcomes}

There were no significant differences in terms of time to gas out and soft diet and length of stay between two groups (Table 3). Inflammatory laboratory findings including WBC, CRP 12 and 24 hours after surgery and the rate of postoperative complications showed no statistical difference. In MPLA group, 4 patients (7.8\%) had surgical site infection (SSI) and one of them was re-admitted for intravenous antibiotics treatment and wound management. In SPLA group, two patients (4.2\%) had SSI and one patient $(2.1 \%)$ had postoperative ileus. Two patients who had SSI were treated with wound evacuation and daily dressing and one patient who had ileus was treated with conservative management including hydration and nasogastric tube insertion. 


\section{TABLE 3}

Post-operatively clinical and hematological outcomes

\begin{tabular}{|llll|}
\hline & MPLA (n=51) & SPLA (n=47) & $\begin{array}{c}\text { p } \\
\text { value }\end{array}$ \\
Gas out (day), median (range) & $1(0-2)$ & $1(1-5)$ & 0.078 \\
\hline Time to soft diet (day), median (range) & $1(0-3)$ & $1(0-8)$ & 0.068 \\
\hline Hospital stay (day), median (range) & $2(1-6)$ & $3(1-9)$ & 0.108 \\
\hline WBC after 12hrs & $10510(1120-$ & $10825(5510-$ & 0.680 \\
WBC after 24hrs & $25800)$ & $19230)$ & 0.587 \\
\hline CRP after 12hrs & $9025(5430-$ & $8766.5(4000-$ & 0.499 \\
\hline CRP after 24hrs & $19760)$ & $15180)$ & 0.652 \\
\hline $\begin{array}{l}\text { Morbidity within 30 days after surgery } \\
\text { (no.), (\%) }\end{array}$ & $8.3(0-20)$ & $9.35(0-31)$ & 0.779 \\
Surgical site infection & $10.83(1-47)$ & $9.88(0-28)$ & \\
Ileus & $4(7.8)$ & $3(6.4)$ & \\
\hline Clavien-Dindo Classification & $4(7.8)$ & $2(4.2)$ & 0.987 \\
I & 0 & $1(2.1)$ & \\
II & & & $2(4.2)$ \\
$\begin{array}{l}\text { MPLA, Multi-Port Laparoscopic Surgery; SPLA, Single-Port Laparoscopic Surgery; WBC, White } \\
\text { Blood Cell; CRP, C-reactive Protein }\end{array}$ & $4(7.8)$ & & \\
\hline
\end{tabular}

Regarding postoperative pain, VAS score 6, 12 and 24 hours after surgery were not significantly different between two groups ( 3 vs $3, p=0.672 ; 4$ vs $3, p=0.319 ; 3$ vs $3, p=0.380$, respectively) (Table 4 ). The total number of analgesics used on postoperative day 0 in the SPLA group was significantly lower than that of the MPLA group ( 1 vs. $1, p=0.011$ ), whereas similar on postoperative day 1 between two groups. 


\section{TABLE 4}

Assessment of the pain after taking appendectomy

\begin{tabular}{llll} 
& MPLA $(\mathbf{n = 5 1 )}$ & SPLA (n=47) & p value \\
\hline $1^{\text {st }}$ VAS*, 6hr, median (range) & $3(0-8)$ & $3(0-8)$ & 0.672 \\
\hline $2^{\text {nd }}$ VAS, 12hr, median (range) & $4(0-7)$ & $3(0-5)$ & 0.319 \\
\hline $3^{\text {rd }}$ VAS, 24hr, median (range) & $3(0-7)$ & $3(1-8)$ & 0.380 \\
\hline Analgesics use on POD \#0 & $1(0-5)$ & $1(0-3)$ & 0.011 \\
\hline Analgesics use on POD \#1 & $1(0-3)$ & $1(0-4)$ & 0.734
\end{tabular}

MPLA, Multi-Port Laparoscopic Surgery; SPLA, Single-Port Laparoscopic Surgery; VAS, Visual Analog Scale; POD, Post Operative Day

\subsection{Patient scar assessment questionnaire scores at 12 weeks postoperatively}

Table 5 shows the comparison of patient scar assessment questionnaire scores at 12 weeks postoperatively between two groups. The PSAQ scores showed that the SPLA group had a better overall outcome than the MPLA group with respect to total score (48 vs. $55 ; p=0.026)$. For the questionnaire sub-items, statistically significant differences were observed in the appearance and consciousness subitems ( 5 and 8 in SPLA vs. 18 and 10 in MPLA, $p=0.002$ and $p=0.005$, respectively), but not in the satisfaction with appearance and symptoms subscales.

TABLE 5

Patient Scar Assessment Questionnaire Scores at 12 weeks postoperatively

\begin{tabular}{|lllll|}
\hline & Best possible score & MPLA $(\mathbf{n}=51)$ & SPLA $(\mathbf{n = 4 7 )}$ & P-value \\
\hline Appearance & 9 & $18(9-31)$ & $15(9-32)$ & 0.002 \\
\hline Consciousness & 6 & $10(6-21)$ & $8(6-24)$ & 0.005 \\
\hline Satisfaction with Appearance & 8 & $16(8-29)$ & $16(8-29)$ & 0.162 \\
\hline Satisfaction with Symptoms & 5 & $10(5-20)$ & $10(5-20)$ & 0.690 \\
\hline Total & 28 & $55(29-96)$ & $48(28-101)$ & 0.026 \\
\hline MPLA, Multi-Port Laparoscopic Surgery; SPLA, Single-Port Laparoscopic Surgery; & \\
\hline
\end{tabular}




\section{Discussion}

In this study, our results showed the feasibility and safety of SPLA compared to MPLA in terms of postoperative clinical outcomes. Operative times were shorter in SPLA group except skin closure time. There was no statistical difference on clinical outcomes including recovery, inflammatory laboratory, morbidity and postoperative VAS score, whereas there was lesser usage of analgesics on the day of surgery in SPLA group. In cosmetic outcomes, the SPLA group had shorter total incision length and better PSAQ results on total score, appearance and consciousness sub-items at 12 weeks postoperatively

Recently, several studies comparing with MPLA and SPLA showed different results on operation time. Some studies showed longer operation time of SPLA[12, 15-17], whereas other showed similar outcomes between two groups. [18-20] In the present study, total operation times was significantly longer in MPLA group than SPLA group (60 min vs $47.5 \mathrm{~min}$ ). In detail, port insertion time tended to be shorter in SPLA group, because the method of using natural orifice as a port insertion site made it easy to achieve pneumo-peritoneum without additional port insertions in other quadrants. Laparoscopic procedure time was shorter in SPLA group and this result may be associated with recent development of laparoscopic instrument including surgical energy device and the accumulated experiences of surgeons. Moreover, we did not require a use of endo-bag and the specimen was extracted through the single incision site during the SPLA, which could reduce the operation time. Unlike other operation times, skin closure time was longer in SPLA group due to the need to suture the relatively long fascia line in the narrow skin incision.

In general, the degree of postoperative pain is mostly caused by trauma to muscles and parietal peritoneum.[21, 22] Since no trocar is inserted through the muscle, it is predicted to show lesser pain in patients who undergo SPLA compared to MPLA [18, 19, 23, 24]. Jatenaonkar et al.[24] and Kye et al.[20] showed that pain scores on day 0 and 1 were significantly less in the SPLA group than MPLA, respectively. One study reported that pain score and the number of using hydromorphone during 12 hours were lower in SPLA group compared to MPLA group [19]. However, the other study reported significantly greater pain scores during the initial 24 hours after SPLA than after conventional approach [16]. In that study, the authors thought that the increased pain with single-port approach was due to a longer fascia incision in the umbilicus. The number of analgesics used on the day of surgery was significantly fewer in the SPLA group, although postoperative VAS scores and the number of analgesics used on the next day of surgery weren't significantly different in both groups. Further study is needed to evaluate the postoperative pain between two surgical approach.

Regarding postoperative complications, previous literatures reported majority of postoperative complications was surgical site infection (SSI) in laparoscopic appendectomy[23, 25, 26], although SSI rate was clearly decreased in laparoscopic approach compared to open method[27, 28] in some studies. These results can be deduced form the fact that inflamed appendix may contaminate the wound which may cause infection in open appendectomy. In studies comparing SPLA and MPLA, Peter et al. in their prospective randomized trial reported that wound infection was 3.3\% in the single-incision group and $1.7 \%$ in the 3-port group, respectively, without statistically significant difference, and SG Jin et al. reported 
$8.7 \%$ of wound complication in single-port method compared to $5.6 \%$ of conventional method[14, 23$]$. A meta-analysis demonstrated that SSI rate was similar between SPLA and MPLA [29]. In our study, there was lower SSI rate in SPLA group than MPLA group (4.2\% vs. $7.8 \%$ ). We think that cleansing the everted umbilicus with betadine once more after routine surgical drape is import for the prevention of surgical site infection in SPLA.

In previous studies, postoperative intra-abdominal abscess was more common in laparoscopic appendectomy than open appendectomy [30,31]. In our study, there was no cases of intra-abdominal abscess formation after appendectomy in both single-port and three-port approach. We routinely performed meticulous irrigation and suction in pelvic cavity, paracolic gutter, and subhepatic region besides the surgical site and we used antibiotics postoperatively after discharge during 1 week for gangrenous or perforated appendicitis as needed.

Since SPLA requires a larger incision than a conventional laparoscopic incision, some researchers have wondered if SPLA can actually cause better cosmesis, because $5 \mathrm{~mm}$ scars are often barely noticeable after a year. Carter et al. [19] used their own Body Image Questionaire and Cosmetic Appearance Scale and reported that cosmetic outcomes after 6 months were excellent and indistinguishable in SPLA and MPLA groups. However, Jategaonkar et al. showed the favorable cosmetic outcomes in SPLA group using Easy-to-use scar grade that was based on patients' subjective feeling about the postoperative scars ( 1 = thrilled, 2 = happy, 3 = not bothered, $4=$ unhappy) [24]. In the current study, patients who underwent SPLA checked better cosmetic outcomes in appearance and consciousness sub-items and total score, while patients' satisfactions with their scars' appearance and consciousness sub-items did not show the significant differences. We think that the better perception of scar image did not translate into improved satisfaction in patients with SPLA.

Our study has several limitations including its retrospective nature, small sample size, and lack of the long-term cosmetic outcomes. Moreover, PSAQ relies on the patient's subjective thoughts. A multicenter randomized prospective study to compare cosmetic outcome and pain assessment using more objective parameters between SPLA and MPLA is needed.

\section{Conclusions}

SPLA is safe and feasible and provides better cosmetic outcomes and less analgesic requirements on the day of surgery compared to MPLA.

\section{Abbreviations}

SPLA: single-port laparoscopic appendectomy; MPLA: multi-port laparoscopic appendectomy; WBC: white blood cell; CRP: C-reactive protein; VAS: visual analog scale; PSAQ: patient scar assessment questionnaire; SSI: surgical site infection. 


\section{Declarations}

\section{Ethics approval and consent to participate}

All methods were carried out in accordance with relevant guidelines and provisions of the Helsinki declaration. The study protocol was approved by the Ethics Committee of Keimyung University Dongsan Hospital (approval number: 2021-03-019), and informed consent was obtained from the participants.

\section{Consent for publication}

Not applicable. Written informed consent was obtained from the patients' guardians for publication of clinical data.

\section{Availability of data and material}

The datasets used and/or analyzed during the current study are available from the corresponding author on reasonable request.

\section{Competing interests}

The authors declare that they have no competing interests.

\section{Funding}

No funding was received for this research.

\section{Authors' contributions}

Data curation and investigation were performed by Sung Uk Bae, Woon Kyung Jeong, and Seong Kyu Baek. Formal analysis was conducted by Kyeong Eui Kim and Sung Uk Bae. Kyeong Eui Kim and In Soo Cho wrote the original draft. Sung Uk Bae, Woon Kyung Jeong, Hyung Jin Kim, and Seong Kyu Baek performed the final review and editing of the draft. All authors read and approved the final manuscript.

\section{Acknowledgements}

Not applicable.

\section{References}


1. Semm K: Endoscopic appendectomy. Endoscopy 1983, 15(2):59-64.

2. Yu MC, Feng YJ, Wang W, Fan W, Cheng $H T$, Xu J: Is laparoscopic appendectomy feasible for complicated appendicitis ?A systematic review and meta-analysis. Int J Surg 2017, 40:187-197.

3. Mentula P, Sammalkorpi H, Leppaniemi A: Laparoscopic Surgery or Conservative Treatment for Appendiceal Abscess in Adults? A Randomized Controlled Trial. Ann Surg 2015, 262(2):237-242.

4. Bae SU, Jeong WK, Baek SK: Single-Port Laparoscopic Interval Appendectomy for Perforated Appendicitis With a Periappendiceal Abscess. Ann Coloproctol 2016, 32(3):105-110.

5. Cho IS, Bae SU, Jeong WK, Baek SK: Single-port laparoscopic appendectomy for acute appendicitis during pregnancy. J Minim Access Surg 2021, 17(1):37-42.

6. Bae SU, Jeong WK, Baek SK: Single-port laparoscopic complete mesocolic excision and central vascular ligation for caecal cancer with apical lymph node metastasis - a video vignette. Colorectal Dis 2018, 20(7):643-644.

7. Lee YS, Kim JH, Kim HJ, Lee SC, Kang BM, Kim CW, Lim SW, Lee SH, Kim JG: Short-term Outcomes of Single-port Versus Multiport Laparoscopic Surgery for Colon Cancer: The SIMPLE Multicenter Randomized Clinical Trial. Ann Surg 2020.

8. Cardinali L, Mazzetti CH, Cadenas Febres A, Repullo D, Bruyns J, Dapri G: Prospective randomized study comparing single-incision laparoscopic versus multi-trocar laparoscopic totally extraperitoneal (TEP) inguinal hernia repair at 2 years. Surg Endosc 2018, 32(7):3262-3272.

9. Lee D, Kim SK, Kim K, Lee JR, Suh CS, Kim SH: Advantages of Single-Port Laparoscopic Myomectomy Compared with Conventional Laparoscopic Myomectomy: A Randomized Controlled Study. J Minim Invasive Gynecol 2018, 25(1):124-132.

10. Morales-Conde S, Del Agua IA, Moreno AB, Macias MS: Postoperative pain after conventional laparoscopic versus single-port sleeve gastrectomy: a prospective, randomized, controlled pilot study. Surg Obes Relat Dis 2017, 13(4):608-613.

11. Esposito C: One-trocar appendectomy in pediatric surgery. Surg Endosc 1998, 12(2):177-178.

12. Frutos MD, Abrisqueta J, Lujan J, Abellan I, Parrilla P: Randomized prospective study to compare laparoscopic appendectomy versus umbilical single-incision appendectomy. Ann Surg 2013, 257(3):413-418.

13. Gasior AC, Knott EM, Holcomb GW, 3rd, Ostlie DJ, St Peter SD: Patient and parental scar assessment after single incision versus standard 3-port laparoscopic appendectomy: long-term follow-up from a prospective randomized trial. J Pediatr Surg 2014, 49(1):120-122; discussion 122.

14. Jin SG, Cho SH, Kim KY, Ahn SK, Cho J, Jung BW, Kim BC, Yoon SN: Transumbilical Single-Incision Laparoscopic-Assisted Appendectomy (TULAA) Is Useful in Adults and Young Adolescents: Comparison with Multi-Port Laparoscopic Appendectomy. Medicina (Kaunas) 2019, 55(6).

15. Vidal O, Valentini M, Ginesta C, Marti J, Espert JJ, Benarroch G, Garcia-Valdecasas JC: Laparoendoscopic single-site surgery appendectomy. Surg Endosc 2010, 24(3):686-691. 
16. Jun Ho Park MD, Kee Hoon Hyun MD, Chan Heun Park MD, Ph.D. SYC, M.D., Won Hyuk Choi MD, Doo Jin Kim MD, Samuel Lee MDPD, Joo Seop Kim MD, Ph.D.: Laparoscopic vs Transumbilical SinglePort Laparoscopic Appendectomy; Results of Prospective Randomized Trial. J Korean Surg Soc 2010, 78(4):213-218.

17. Clerveus M, Morandeira-Rivas A, Moreno-Sanz C, Herrero-Bogajo ML, Picazo-Yeste JS, Tadeo-Ruiz G: Systematic review and meta-analysis of randomized controlled trials comparing single incision versus conventional laparoscopic appendectomy. World J Surg 2014, 38(8):1937-1946.

18. Buckley FP, 3rd, Vassaur H, Monsivais S, Jupiter D, Watson R, Eckford J: Single-incision laparoscopic appendectomy versus traditional three-port laparoscopic appendectomy: an analysis of outcomes at a single institution. Surg Endosc 2014, 28(2):626-630.

19. Carter JT, Kaplan JA, Nguyen JN, Lin MY, Rogers SJ, Harris HW: A prospective, randomized controlled trial of single-incision laparoscopic vs conventional 3-port laparoscopic appendectomy for treatment of acute appendicitis. J Am Coll Surg 2014, 218(5):950-959.

20. Kye BH, Lee J, Kim W, Kim D, Lee D: Comparative study between single-incision and three-port laparoscopic appendectomy: a prospective randomized trial. J Laparoendosc Adv Surg Tech A 2013, 23(5):431-436.

21. Chouillard E, Dache A, Torcivia A, Helmy N, Ruseykin I, Gumbs A: Single-incision laparoscopic appendectomy for acute appendicitis: a preliminary experience. Surg Endosc 2010, 24(8):18611865.

22. Kim HJ, Lee JI, Lee YS, Lee IK, Park JH, Lee SK, Kang WK, Cho HM, You YK, Oh ST: Single-port transumbilical laparoscopic appendectomy: 43 consecutive cases. Surg Endosc 2010, 24(11):27652769.

23. St Peter SD, Adibe OO, Juang D, Sharp SW, Garey CL, Laituri CA, Murphy JP, Andrews WS, Sharp RJ, Snyder CL et al: Single incision versus standard 3-port laparoscopic appendectomy: a prospective randomized trial. Ann Surg 2011, 254(4):586-590.

24. Jategaonkar PA, Yadav SP: Single site multiport umbilical laparoscopic appendicectomy versus conventional multiport laparoscopic appendicectomy in acute settings. Ann R Coll Surg Engl 2014, 96(6):452-457.

25. Katsuno G, Nagakari K, Yoshikawa S, Sugiyama K, Fukunaga M: Laparoscopic appendectomy for complicated appendicitis: a comparison with open appendectomy. World J Surg 2009, 33(2):208214.

26. Lee YS, Kim JH, Moon EJ, Kim JJ, Lee KH, Oh SJ, Park SM, Hong TH: Comparative study on surgical outcomes and operative costs of transumbilical single-port laparoscopic appendectomy versus conventional laparoscopic appendectomy in adult patients. Surg Laparosc Endosc Percutan Tech 2009, 19(6):493-496.

27. Biondi A, Di Stefano C, Ferrara F, Bellia A, Vacante M, Piazza L: Laparoscopic versus open appendectomy: a retrospective cohort study assessing outcomes and cost-effectiveness. World J Emerg Surg 2016, 11(1):44. 
28. Takami T, Yamaguchi T, Yoshitake H, Hatano K, Kataoka N, Tomita M, Makimoto S: A clinical comparison of laparoscopic versus open appendectomy for the treatment of complicated appendicitis: historical cohort study. Eur J Trauma Emerg Surg 2019.

29. Aly OE, Black DH, Rehman H, Ahmed I: Single incision laparoscopic appendicectomy versus conventional three-port laparoscopic appendicectomy: A systematic review and meta-analysis. Int $J$ Surg 2016, 35:120-128.

30. Schlottmann F, Sadava EE, Pena ME, Rotholtz NA: Laparoscopic Appendectomy: Risk Factors for Postoperative Intraabdominal Abscess. World J Surg 2017, 41(5):1254-1258.

31. Cao J, Tao F, Xing H, Han J, Zhou X, Chen T, Wang H, Li Z, Zhou Y, Wang S et al: Laparoscopic Procedure is Not Independently Associated With the Development of Intra-Abdominal Abscess After Appendectomy: A Multicenter Cohort Study With Propensity Score Matching Analysis. Surg LaparosC Endosc Percutan Tech 2017, 27(5):409-414.

\section{Figures}
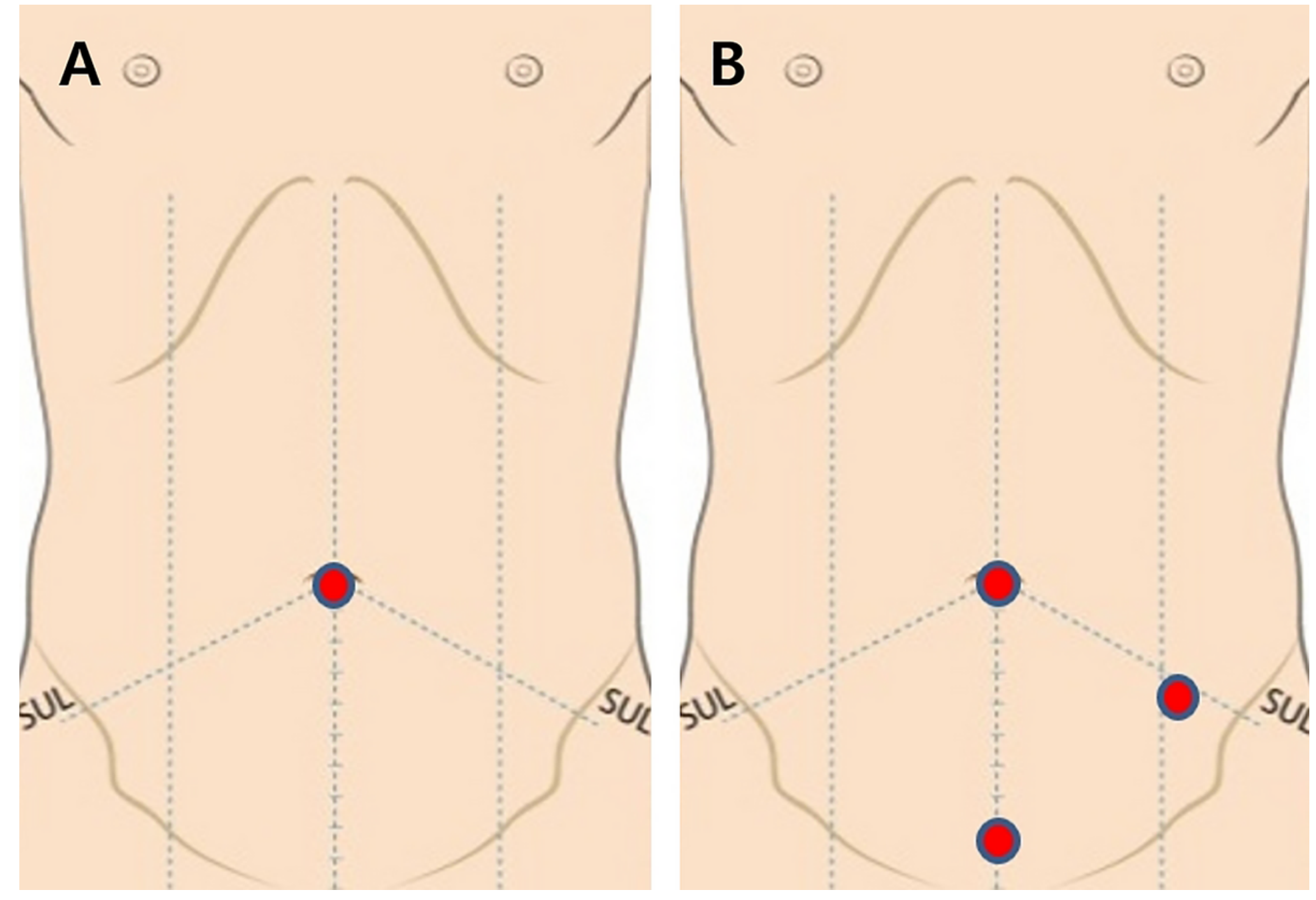

Figure 1 
(a) Port placement for single-port laparoscopic appendectomy. (b) Port placement for multi-port laparoscopic appendectomy.
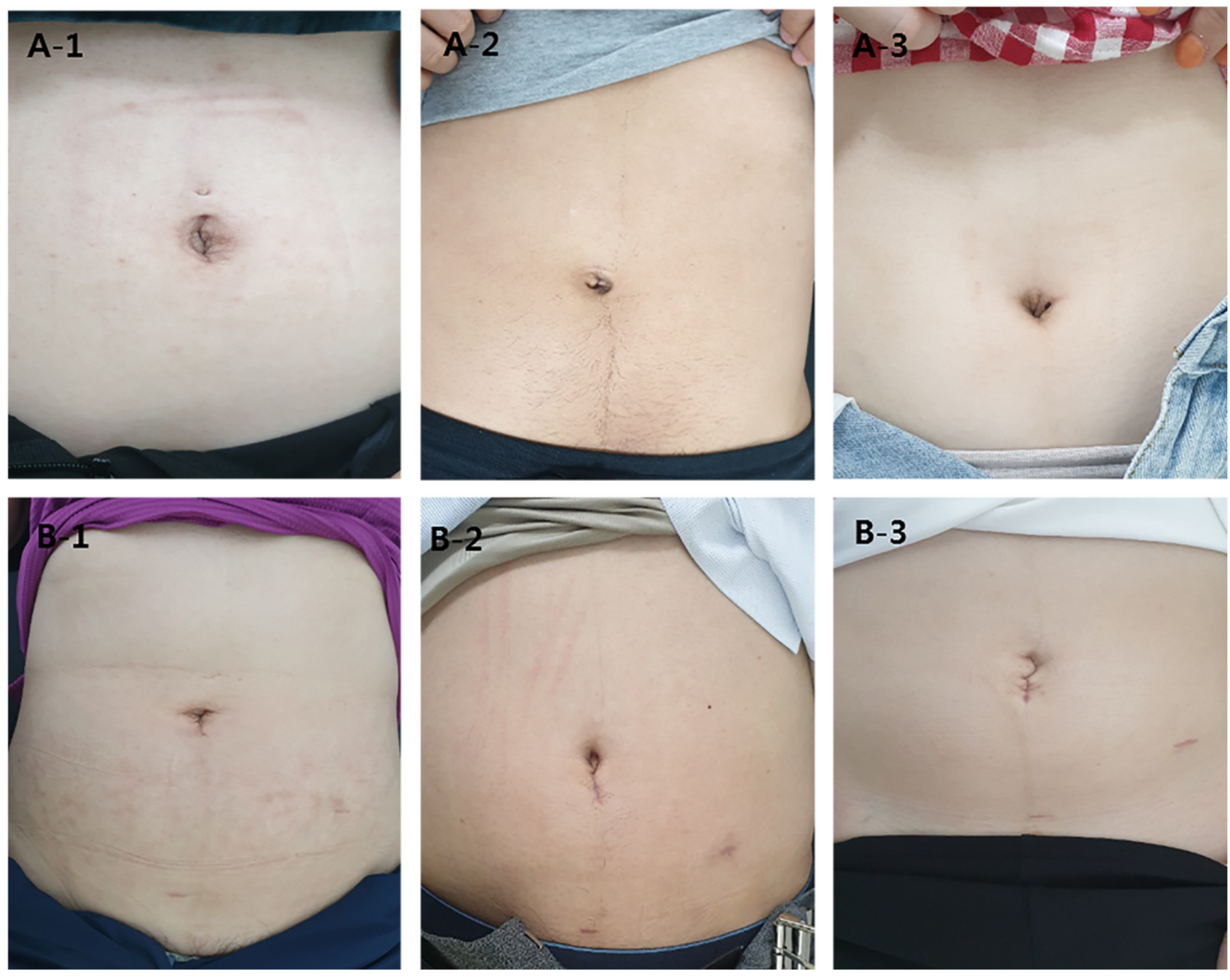

Figure 2

(a) Postoperative scar: (A) single-port laparoscopic appendectomy and (B) multi-port laparoscopic appendectomy. 